\title{
The role of the hydrogen evolution reaction in the solid-electrolyte interphase formation mechanism for "Water-in-Salt" electrolytes
}

\author{
Nicolas Dubouis, ${ }^{\mathrm{a}, \mathrm{b}}$ Pierre Lemaire, ${ }^{\mathrm{a}, \mathrm{b}, \mathrm{c}}$ Boris Mirvaux, ${ }^{\mathrm{a}, \mathrm{b}}$ Elodie Salager ${ }^{\mathrm{b}, \mathrm{d}}$, Michael \\ Deschamps $^{\mathrm{b}, \mathrm{d}}$, Alexis Grimaud $\mathrm{d}^{\mathrm{a}, \mathrm{b}, \mathrm{c} *}$
}

${ }^{\text {a }}$ Chimie du Solide et de l'Energie, Collège de France, UMR 8260, 75231 Paris Cedex 05, France

${ }^{\mathrm{b}}$ Réseau sur le Stockage Electrochimique de 1'Energie (RS2E), CNRS FR3459, 33 rue Saint Leu, 80039 Amiens Cedex, France

${ }^{\mathrm{c}}$ Sorbonne Université, Paris, France

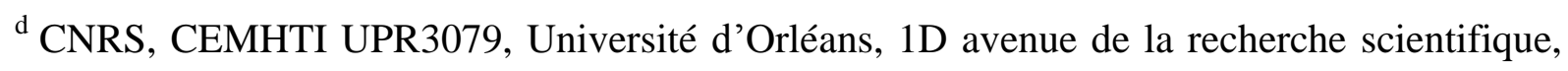
45071 Orléans Cedex 2, France

email: alexis.grimaud@ college-de-france.fr 
ABSTRACT: Aqueous Li-ion batteries have long been envisioned as safe and green energy storage technology, but have never commercially realized owing to the limited electrochemical stability window of water, which drastically hampers their energy density. Recently, Water-in-Salt electrolytes (WiSEs) in which a large amount of organic salts is dissolved into water were proposed to allow for assembling $3 \mathrm{~V} \mathrm{Li}$-ion batteries. Hereby, our attention focused on the fate of water at the electrochemical interface under negative polarization and the potential reactivity of TFSI anions with products originating from the water reduction. Hence, combining analysis of bulk electrolytes with electrochemical measurements on model electrodes and operando characterizations, we were able to demonstrate that hydroxyls generated during the hydrogen evolution reaction can chemically react with TFSI and catalyze the formation of a fluorinated solid-electrolyte interphase (SEI) that prevents further water reduction. Mastering this new SEI formation path with the chemical degradation of TFSI anions mediated by the electrochemical reduction of water can therefore open new avenues for the future development of not only WiSEs but also Li batteries functioning in organic electrolytes. 


\section{Introduction}

Thanks to the development of high specific energy insertion materials, lithium-ion batteries (LiBs) are nowadays well established as the leading technology to feature mobility and meet the renewable energy storage needs. ${ }^{1}$ Today, typical LiBs materials are working at voltages higher than $4 \mathrm{~V}$ for positive electrodes, while negative electrodes operate at potential lower than $1 \mathrm{~V}\left(\mathrm{vs} . \mathrm{Li}^{+} / \mathrm{Li}\right.$ ), well below the thermodynamical stability of carbonate-based electrolytes commonly employed. This is made possible thanks to the initial degradation of the electrolyte, either at the open-circuit voltage (OCV) or during the first initial cycles, forming an insulating but ionically conducting layer on the surface of the electrode called the solid-electrolyte interphase (SEI). ${ }^{2-4}$ In parallel with the development of LIBs based on carbonated electrolytes, the feasibility of aqueous LiBs has been investigated since early 1990 's, ${ }^{5,6}$ motivated by environmental, safety and cost challenges. However, the development of these aqueous devices faces two main challenges. First, the electrochemical window in which water is thermodynamically stable is limited to $1.23 \mathrm{~V}$, well below typical organic electrolytes. Second, the formation of a stable and electronically insulating SEI in aqueous electrolytes appears challenging owing to the greater solubility of ionic compounds in water than in organic electrolytes. ${ }^{7}$ Nonetheless, inspired by organic superconcentrated electrolytes, ${ }^{8,9}$ Suo et al. recently proposed a new class of "aqueous" electrolytes, described as Water-in-Salt Electrolytes (WiSEs), obtained by dissolving large quantities of lithium bis(trifluoromethanesulfonyl)amide (LiTFSI) salt in water (more than 20 moles per kilogram of water) and in which a fluorinated based SEI was reported to be formed on the surface of electrodes. ${ }^{10}$ Thus, these so-called WiSEs have recently been investigated in depth for the realization of practical $\mathrm{LiBs}^{11-15}$, but also for other applications such as sodium-ion, ${ }^{16}$ potassium-ion, ${ }^{17}$ lithium-air ${ }^{18}$ batteries or even supercapacitors. ${ }^{19}$ 
It is well established that the formation of the SEI on the surface of the negative electrode that prevents water reduction during the cell operation involves TFSI degradation. ${ }^{10}$ Hence, it was proposed that TFSI anions are directly electrochemically reduced during the cell operation on the negative electrode, ${ }^{10,20}$ therefore nothing was mentioned about the possible role of water could have in this degradation reaction. This serves us as a motivation to investigate the degradation mechanism of TFSI anions in WiSEs and more so the role that water, if any, could play in catalyzing this degradation and on the formation of the SEI. Using electrochemical measurements combined with operando and ex-situ material and spectrometric characterization techniques, we demonstrate that TFSI anions can allow for the deposition of a passivating layer owing to its chemical instability in the strongly alkaline environment created by the reduction of water at the negative electrode. This result could be of great help in future strategies aiming towards the development of aqueous and organic batteries with enhanced energy density.

\section{Results and discussion}

\section{Water-in-Salt Electrolytes vs. Saturated Electrolytes: Modification of Water Physical}

Properties. Besides the possible electrochemical reduction of TFSI anions, there is also the feasibility to reduce water by cleaving $\mathrm{O}-\mathrm{H}$ bonds. ${ }^{21,22}$ To check this hypothesis, we first investigated the influence of adding salt on the structure of water by the means of FourierTransform infrared spectroscopy (FTIR). FTIR absorbance spectra shown in Figure 1 demonstrate that the water bending mode $\left(\right.$ at $\left.\sim 1,625 \mathrm{~cm}^{-1}\right)$ is not affected by the increase of LiTFSI concentration. On the contrary, drastic modifications for the broad signal centered at around $3,300 \mathrm{~cm}^{-1}$ and characteristic of $\mathrm{O}-\mathrm{H}$ bond stretching mode are observed. Indeed, with a concentration of LiTFSI above $1 \mathrm{~m}$, new peaks at higher wavenumbers appear, 
resulting from the presence of new environments for water molecules, such as contact ion pairs (CIP) and ionic aggregates (AGGs) as suggested by Borodin et al.. ${ }^{23}$ The presence of those new environments at higher wavenumbers traduces the reinforcement of the $\mathrm{O}-\mathrm{H}$ bond which could therefore explain the lowest reactivity of the water upon electrolysis conditions observed in WiSEs. ${ }^{10,24,25}$

Nevertheless, this result is counter intuitive as first since, owing to the strong Lewis acidity of $\mathrm{Li}^{+}$cation, a depletion of the electronic density of water and therefore a weakening of the $\mathrm{O}-\mathrm{H}$ bond of water molecules would have been expected. Hence, to discriminate the relative influences of the cations and anions, similar analysis were performed on saturated solutions using $\mathrm{LiNO}_{3}(\sim 11 \mathrm{~m})$ and $\mathrm{LiCl}(\sim 18 \mathrm{~m})$ salts in water. At these concentrations, the number of water molecules per ion of lithium, respectively 5 for $11 \mathrm{~m} \mathrm{LiNO}_{3}$ and 3 for $18 \mathrm{~m}$ $\mathrm{LiCl}$, does not allow for the formation of a complete solvation shell for cations. Interestingly, the stretching mode for the $\mathrm{O}-\mathrm{H}$ bond of water molecules appears to be only weakly affected for concentrated $\mathrm{LiNO}_{3}$ and $\mathrm{LiCl}$ solutions when compared to concentrated TFSI solution (Figure 1b), and no clear shift toward higher wavenumbers was observed. This result confirms that the use of a high concentration of strongly coordinating $\mathrm{Li}^{+}$cations cannot explain the consolidation of the $\mathrm{O}-\mathrm{H}$ molecules in TFSI-based WiSEs, which would rather arise from the anion. 


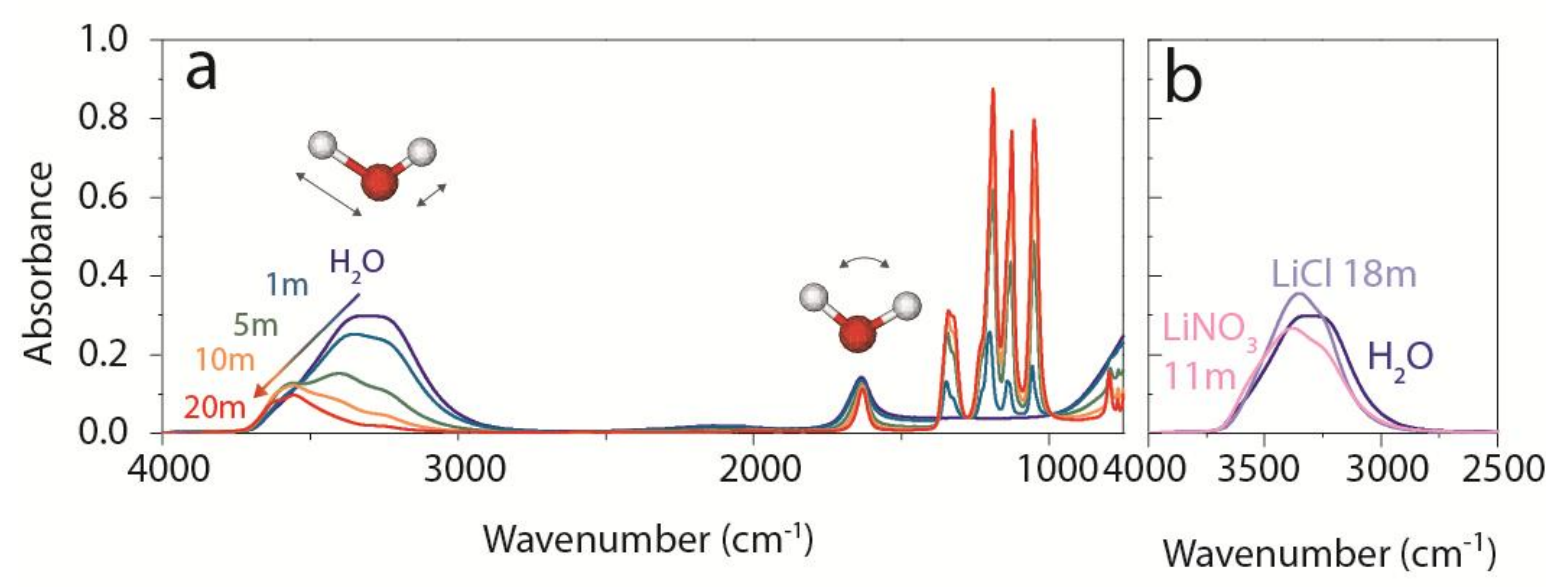

Figure 1. FTIR absorbance spectra of a) LiTFSI based electrolytes at several molalities (1 m light blue, $5 \mathrm{~m}$ green, $10 \mathrm{~m}$ orange and $20 \mathrm{~m}$ red) compared with the one of pure water (blue) and of b) $\mathrm{LiNO}_{3}$ saturated solution ( 11 m, pink) and $\mathrm{LiCl}$ saturated solution $(\sim 18 \mathrm{~m}$, purple).

To explore further the role of the different ions on the solvation of water molecules and their electronic environement, ${ }^{1} \mathrm{H},{ }^{7} \mathrm{Li}$ and ${ }^{19} \mathrm{~F}$ nuclear magnetic resonance (NMR) spectroscopy was used. As shown in Figure 2, the ${ }^{1} \mathrm{H}$ signal is found to move to lower chemical shifts with the LiTFSI concentration. This shift traduces a shielding of protons from the water molecules due to an increase of their surrounded electronic density, consistent with the increase of the $\mathrm{O}-\mathrm{H}$ bond strength previously observed by FTIR (Figure 1). In comparison, a much reduced shielding is found for water protons in saturated $\mathrm{LiNO}_{3}$ and $\mathrm{LiCl}$ solutions (Figure S1), hence suggesting the specific role played by TFSI anions in modifying the $\mathrm{O}-\mathrm{H}$ bond. To further discriminate the role of TFSI anions from the one played by $\mathrm{Li}^{+}$ cations, ${ }^{1} \mathrm{H}$ NMR spectra for $1 \mathrm{~m} \mathrm{LiCl}$, LiTFSI and KTFSI solutions were then compared (Figure 2b). While limited shielding was observed for the water proton for $1 \mathrm{~m} \mathrm{LiCl}(4.65$ 
ppm vs. 4.7 ppm for pure $\mathrm{H}_{2} \mathrm{O}$ ), the ${ }^{1} \mathrm{H}$ signal for water is shifted to lower chemical shift for 1 m LiTFSI (4.6 ppm). Moreover, an even greater shift is observed for $1 \mathrm{~m} \mathrm{KTSFI} \mathrm{(4.5} \mathrm{ppm).}$ These results corroborate the critical role played by TFSI anions on consolidating the O-H bonds. Looking first into the effect of the anions, this higher shielding of the ${ }^{1} \mathrm{H}$ water signal for LiTFSI compared to $\mathrm{LiCl}$ must be the result of a reinforcement of water electronic density due to a stronger interaction of water with TFSI anions. For the cations, the higher shielding observed for $\mathrm{K}^{+}$can be rationalized by the weaker Lewis acididty of $\mathrm{K}^{+}$than $\mathrm{Li}^{+}$cations. ${ }^{26} \mathrm{In}$ definitive, we can conclude that the specific shielding of protons observed in LiTFSI-based WiSEs is mostly arising from TFSI anions, rather than from $\mathrm{Li}^{+}$.

Turning to the ${ }^{7} \mathrm{Li}$ and ${ }^{19} \mathrm{~F}$ NMR measurements, we first observe a decrease to lower chemical shift for the ${ }^{7} \mathrm{Li}$ signal with increasing LiTFSI concentration which results from an increase of the electronic density around $\mathrm{Li}^{+}$cations (Figure 2c). A possible origin for such increase of the electronic density around $\mathrm{Li}^{+}$is the formation of new ionic structures such as CIPs or AGGs in which a greater proximity between cations and anions is observed. Similarly, a shift to more shielded environments (greater electronic density) is also observed for the ${ }^{19} \mathrm{~F}$ signal when increasing the LiTFSI concentration suggesting greater anion-anion interactions (Figure 2d). Altogether, these results can be rationalized as follow. At low concentrations, TFSI anions are well separated by water molecules and no TFSI-TFSI interactions can be observed (Figure 2e). Increasing the salt concentration, water molecules which preferentially solvate $\mathrm{Li}^{+}$become less available to separate TFSI anions. This observation demonstrates the destruction of the water-water hydrogen bonds which are replaced by water-TFSI H-bonding interactions ${ }^{27}$ and leads to a greater proximity between TFSI molecules as well as TFSI with $\mathrm{Li}^{+}$is enhanced, as previously proposed. ${ }^{10}$ 
Overall, combining FTIR and NMR results, the structure of the WISEs electrolytes could be simply described as a solvate ionic liquid (IL), in which a large and "soft" $\left[\mathrm{Li}\left(\mathrm{H}_{2} \mathrm{O}\right)_{2 . \mathrm{x}}\right]^{+}$cation is directly interacting with a "soft" TFSI anion as no free solvent molecules can separate them (Figure 2e). ${ }^{28}$
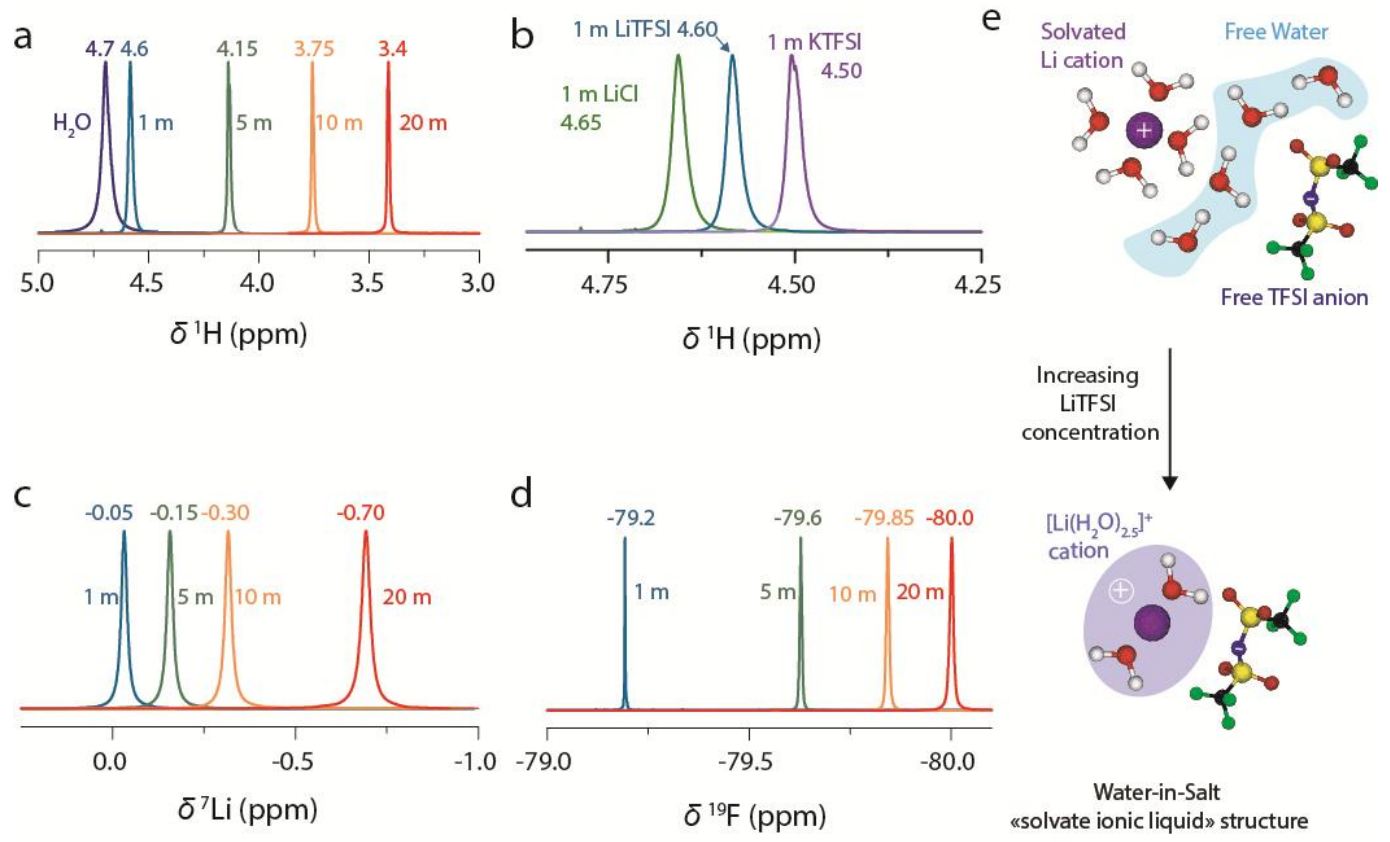

Figure 2. Normalized NMR spectra of "aqueous" electrolytes showing the ${ }^{1} \mathrm{H}$ chemical shift of water molecules in presence of a) LiTFSI at several molalities ( $1 \mathrm{~m}$ light blue, $5 \mathrm{~m}$ green, $10 \mathrm{~m}$ orange and $20 \mathrm{~m}$ red) compared with the one of pure water (dark blue) and b) $\mathrm{LiCl}$ (green), LiTFSI (blue) and KTFSI (purple) at $1 \mathrm{~m}, \mathrm{c}){ }^{7} \mathrm{Li}$ NMR spectra and d) ${ }^{19} \mathrm{~F}$ NMR spectra of LiTFSI electrolytes and e) schematic evolution of the solvation shell of $\mathrm{Li}^{+}$cations and TFSI anions from diluted electrolytes (top) to WiSEs (bottom). 
Investigation of WiSEs Electrochemical Window on Model Electrodes. Having confirmed the critical role of TFSI anions on the destructuration of the network of water molecules, we then study the electrochemical water splitting in WiSEs on two flat model electrodes, glassy carbon (GC) and polycrystalline platinum, respectively known to possess poor and good electrocatalytic activity towards water reduction. Data will be described here in terms of onset potentials (potential required to attain a certain current density) for both the anodic and the cathodic processes, bearing in mind that the notion of overpotential usually employed by the electrocatalysis community is not relevant as the Nernst equilibrium potential should be corrected for the modification of the water activity which differs from 1 . The electrochemical results presented in Figure 3a confirm that the anodic stability of water increases with the LiTFSI concentration, independently on the electrode material (Pt or GC). As proposed by Coustan $e t a l .{ }^{24}$ and latter on rationalized by others, ${ }^{29,30}$ the screening by TFSI anions of the positively charged electrode prevents the migration of water to the surface of the electrode, which increases the onset potential for the oxygen evolution reaction (OER: $\mathrm{H}_{2} \mathrm{O}->2 \mathrm{H}^{+}+1 / 2$ $\left.\mathrm{O}_{2}+2 \mathrm{e}^{-}\right)$. Regarding the cathodic behavior, no real trend was found, as the cathodic currents are similar within the range of error bars due to ohmic drop compensation (between $15 \Omega$ for $1 \mathrm{~m}$ electrolytes up to $125 \Omega$ for $20 \mathrm{~m}$ electrolytes).

Intrigued by the lack of modification of the cathodic behavior with increased LiTFSI concentration, the electrochemical window was widened and rotating disk setup was used to avoid limitations related to mass diffusion. Surprisingly, a broad and large reduction peak was observed for $20 \mathrm{~m}$ LiTFSI, followed by another reduction event. Since rotation is applied, this phenomenon is unlikely arising from a diffusion-limited process for which a plateau would be observed. 

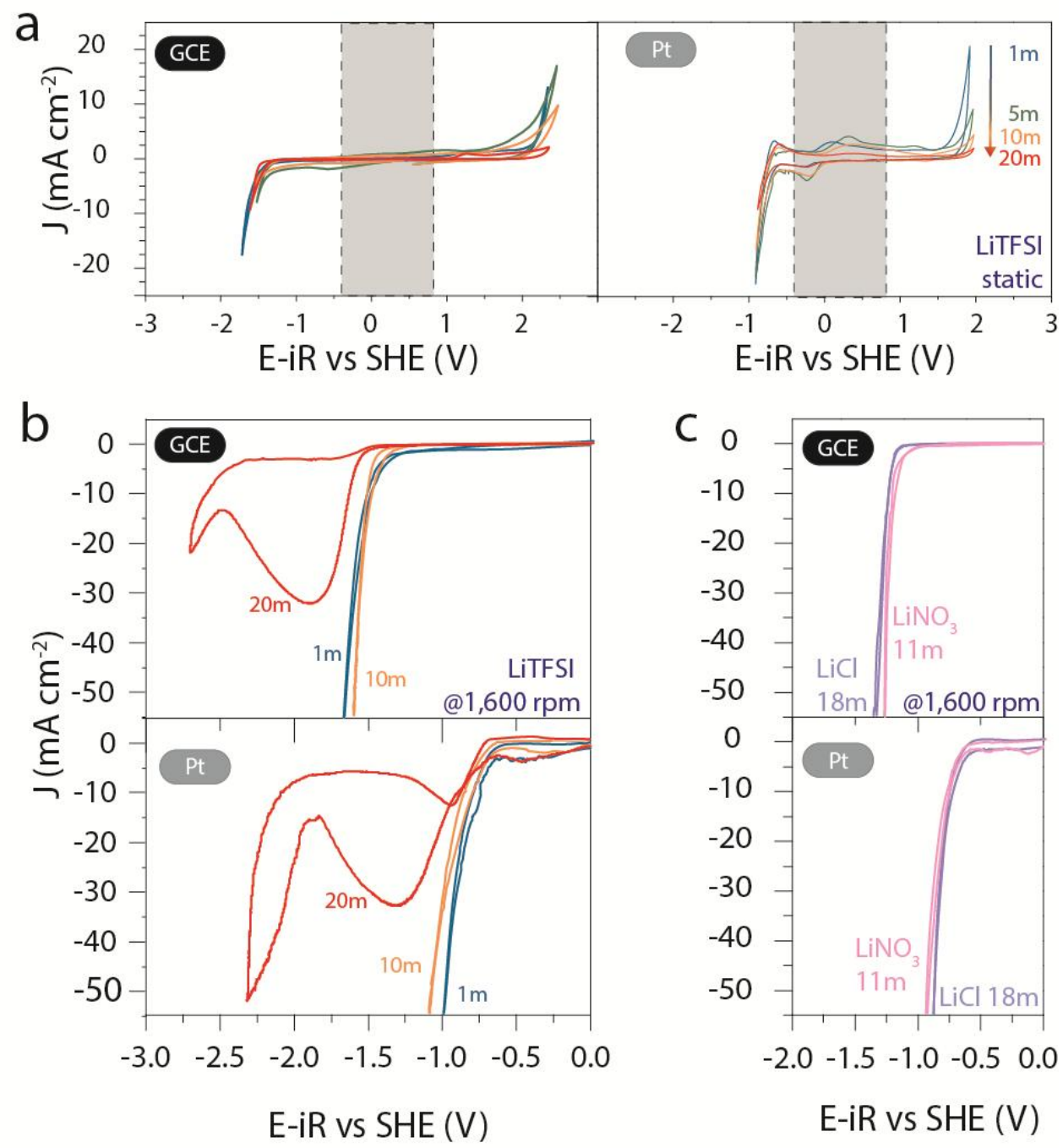

Figure 3. Cyclic voltammograms recorded at $100 \mathrm{mV} \cdot \mathrm{s}^{-1}$ a) in static conditions over glassy carbon (left) and platinum (right) electrodes in $1 \mathrm{~m}$ (blue), $5 \mathrm{~m}$ (green), $10 \mathrm{~m}$ (orange) and 20 m (red) LiTFSI aqueous electrolytes and b) on glassy carbon (top) and platinum (bottom) disk electrodes rotated at 1,600 rpm in $1 \mathrm{~m}$ (blue) $10 \mathrm{~m}$ (orange) and $20 \mathrm{~m}$ (red) LiTFSI aqueous electrolytes and c) same rotating disk experiment performed in $\mathrm{LiNO}_{3}$ saturated solution $(\sim 11$ $\mathrm{m}$, pink) and $\mathrm{LiCl}$ saturated solution ( $18 \mathrm{~m}$, purple). On a) grey area represents the thermodynamic stability window of water in the considering of pure water at $\mathrm{pH}=7$. 
However, at this stage of the study, the electrochemical processes at the origin of this first reduction peak remain unclear. We can first observe that its onset potential for this reduction peak is close to the one measured for water reduction in less concentrated electrolytes (1 m and $10 \mathrm{~m}$ ) (Figure $3 \mathrm{~b}$ ). Similar experiments were thus performed in saturated $\mathrm{LiNO}_{3}$ and $\mathrm{LiCl}$ electrolytes to assess the role played by TFSI anions in this reduction process. As shown in Figure 3c, a reduction process with a similar onset potential is observed for $\mathrm{LiNO}_{3}$ and $\mathrm{LiCl}$, however no reduction peak was observed on $\mathrm{GC}$ and platinum electrodes for these saturated electrolytes, unlike what was found for LiTFSI electrolytes (Figure 3b). Altogether, these electrochemical results demonstrate that the onset potential for reduction is independent on the anion and its concentration, while the apparition of a cathodic peak is only observed in LiTFSI-based WiSEs.

\section{Growth of a passivating layer on the electrodes upon water reduction and $\mathrm{LiOH}$} formation. Another specific feature noticed for $20 \mathrm{~m}$ LiTFSI is the quasi absence of reduction current observed during the backward scan which could indicate the deposition of a passivating layer, as already noticed in ionic liquid. ${ }^{31}$ To confirm this hypothesis, electrochemical quartz crystal microbalance (EQCM) was used. At relatively mild reducing potential, no current and no modification of the quartz resonance frequency is observed (Figure 4a). When lowering the potential below $-1.7 \mathrm{~V}$ vs. SHE, a concomitant increase of the cathodic current and a decrease of the quartz resonance frequency are measured, indicative of a gain of mass. When reaching the top of the cathodic peak, the mass stabilizes before to further increase when entering the solvent reduction region at potential lower than $-2.5 \mathrm{~V}$ vs. SHE. On the backward scan, a continuous loss of weight is measured, revealing the desorption of ions previously adsorbed at the interface under negative polarization. ${ }^{32-35}$ Indeed, below the point of zero charge (PZC) of the electrodes, $\mathrm{Li}^{+}$cations are continuously 
adsorbed to screen the negative charge on the surface of the electrode. For WiSEs, these solvated $\left[\mathrm{Li}\left(\mathrm{H}_{2} \mathrm{O}\right)_{2 . x}\right]^{+}$cations are not only surrounded by water molecules, but form pairs with TFSI anions as we observed by NMR and previously discussed by MD simulations. ${ }^{29,30}$ Thus, TFSI anions absorb on the electrode surface together with $\left[\mathrm{Li}\left(\mathrm{H}_{2} \mathrm{O}\right)_{2 . \mathrm{x}}\right]^{+}$cations. Finally, after reaching back a potential at which no current is measured, the mass stabilizes with an irreversible gain of $5 \mu \mathrm{g} . \mathrm{cm}^{-2}$. This irreversible gain of mass takes place in the potential range highlighted by the grey area on Figure 4a, which matches well with the potential at which a reduction peak is observed during the cyclic voltammetry. Analyzing the evolution of the mass with the charge passed during the cathodic process (Figure S2), the presence of at least two distinct processes are confirmed. Unfortunately, the exact molecular weight of the deposited product could not be extracted, as discussed in the supplementary materials. Furthermore, it is worth mentioning that all the electrochemical measurements show that the formation of this film does not totally suppress the electrolyte degradation at very low potentials below $-2.5 \mathrm{~V}$ vs. SHE where large cathodic current is measured. As discussed by Suo et al., this can be in part explained by the increased probability for electrons to undergo a tunneling process through this poorly conductive layer when going towards more negative potentials. $^{20}$ 


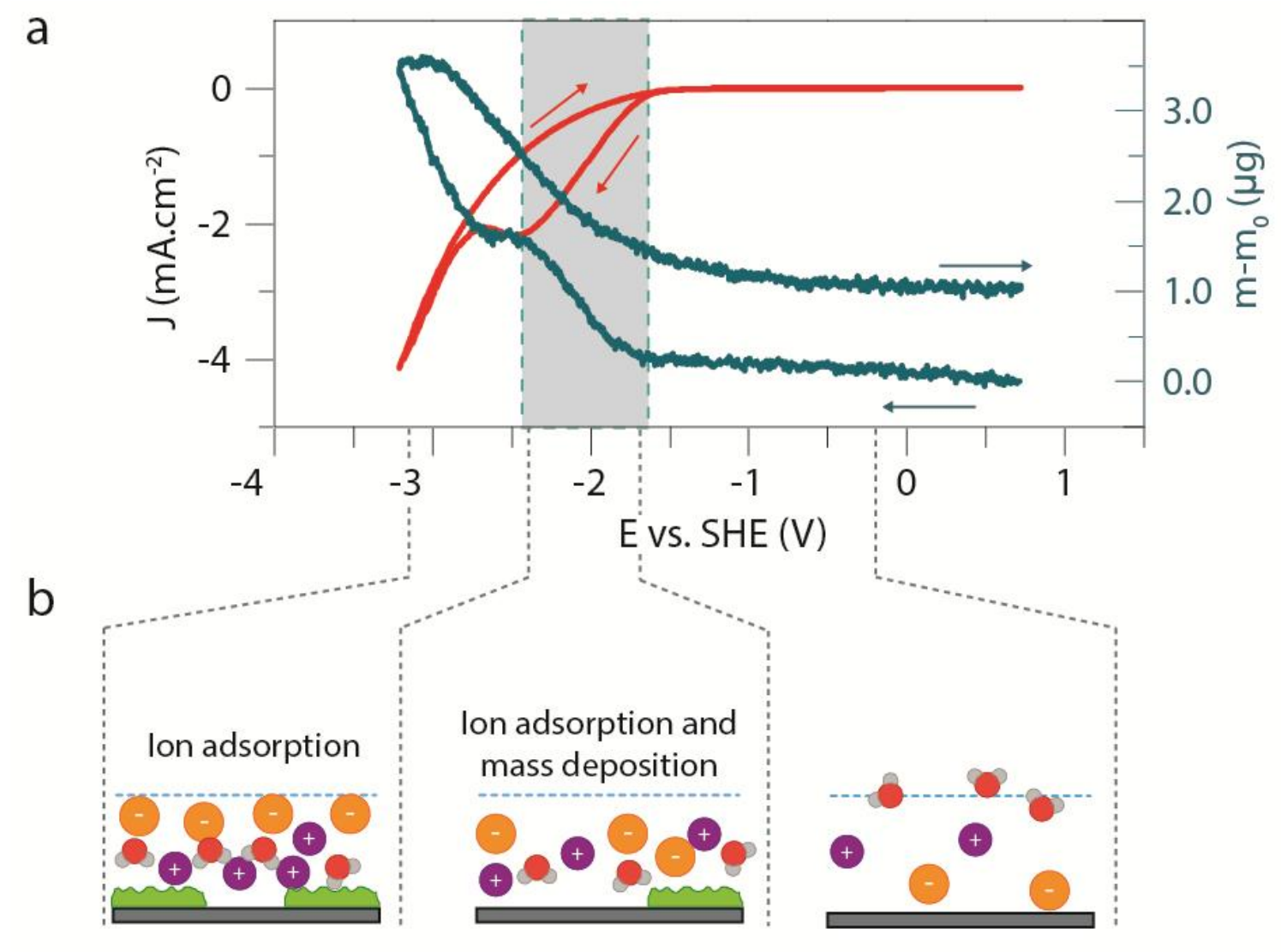

C
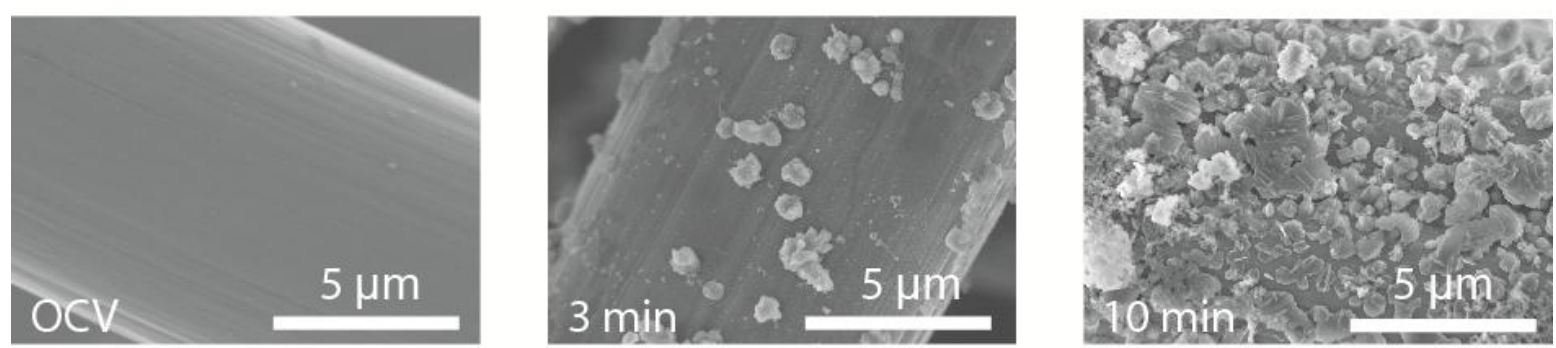

Figure 4. a) Cyclic voltammogram recorded at $5 \mathrm{mV}^{-1} \mathrm{~s}^{-1}$ on a carbon electrochemical quartz microbalance electrode in $20 \mathrm{~m}$ LiTFSI solution showing the intensity (red) and the mass deposited on the electrode (blue), b) schematic representation of the phenomena taking place during the forward scan of the cyclic voltammogram and c) SEM pictures of gas diffusion layer electrodes just wetted in $20 \mathrm{~m}$ LiTFSI and rinsed (left), hold at $-1.8 \mathrm{~V}$ vs. SHE for $3 \mathrm{~min}$ (middle) and for $10 \mathrm{~min}$ (right) and rinsed. 
To confirm that the gain of mass observed in this potential range was due to the deposition of a film on the electrode surface, porous gas diffusion layer (GDL) electrodes were hold at $-1.8 \mathrm{~V}$ vs. SHE in $20 \mathrm{~m}$ LiTFSI solution and analyzed post mortem by scanning electron microscopy (SEM). After holding the GDL electrode for 3 min (Figure 4c), small deposits that are not observed when simply soaking the electrode at the OCV could be seen. After 10 minutes holding, the fibers are almost fully covered by a film made of aggregates of particles with a flake morphology (Figure S3). Finally, the chemical composition of this film was analyzed by energy dispersive X-ray spectrometry (EDX) where traces of fluorine and sulfur were observed (Figure S4). Nevertheless, the relative instability of the film under the electron beam prevents from a proper quantification and identification of its chemical composition. 


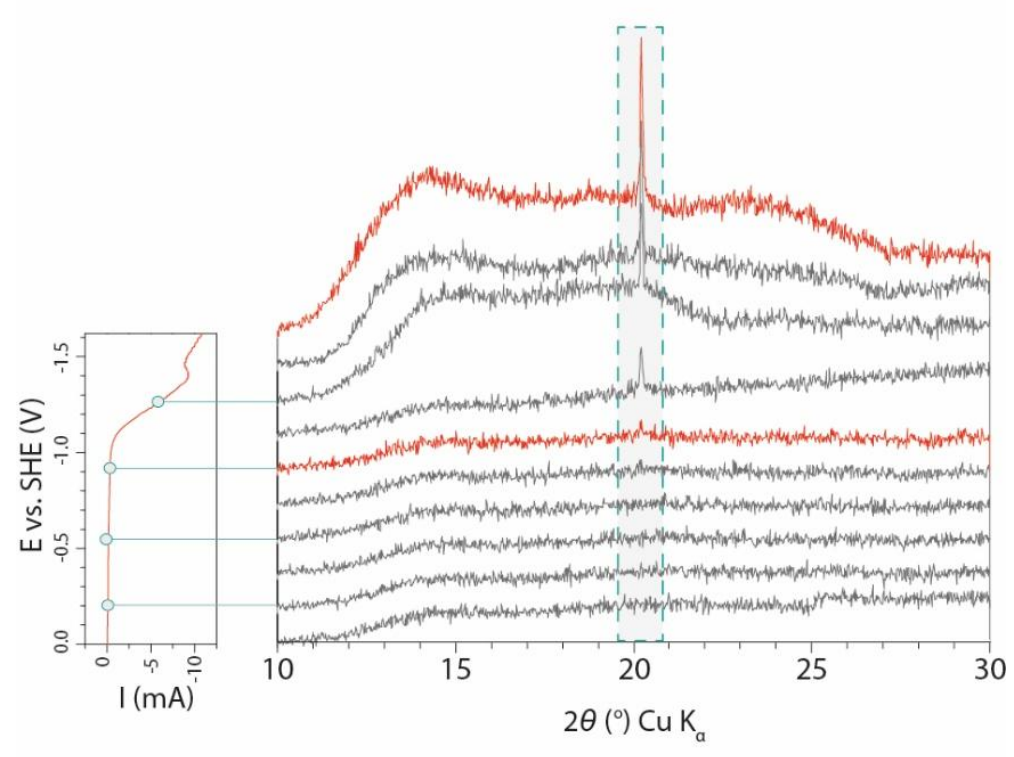

b

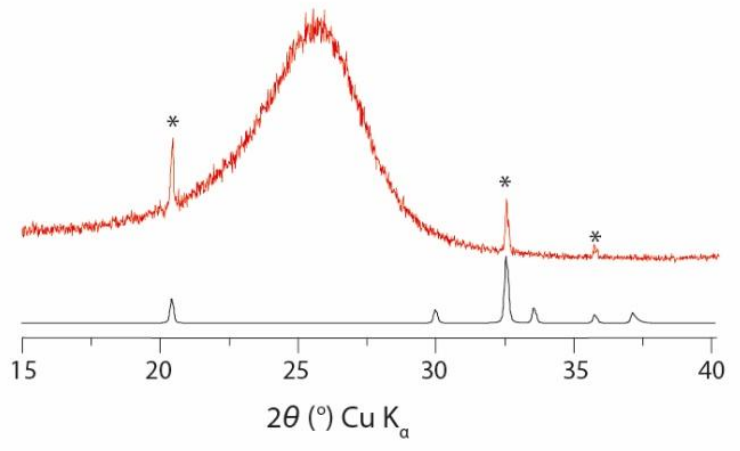

Figure 5. a) Linear sweep voltammogram at recorded at $0.3 \mathrm{mV} \cdot \mathrm{s}^{-1}$ on a gas diffusion layer electrode in 20 m LiTFSI followed by operando XRD and b) diffractogram of a gas diffusion layer electrode hold a $-1.8 \mathrm{~V}$ vs. SHE for $10 \mathrm{~min}$ and rinsed (red) compared with $\mathrm{LiOH}$ reference pattern (grey).

To circumvent this limitation, operando X-ray diffraction (XRD) was carried out. As shown in Figure 5a, the growth of a crystalline compound, out of a large background signal, characterized by a peak at a diffraction angle of around $20^{\circ}$ is observed starting from $\sim-0.7 \mathrm{~V}$ vs. SHE. To fully ascertain this assignment, ex-situ XRD measurement was taken on a GDL electrode held at $-1.8 \mathrm{~V}$ vs. SHE for 10 minutes (see methods and Figure S6). The XRD 
pattern reveals the presence of several peaks corresponding to crystalline lithium hydroxide $(\mathrm{LiOH})$, hence demonstrating its precipitation upon reduction in WISEs. The absence of other crystalline material detected by $\mathrm{XRD}$, while traces of sulfur and fluorine were noticed by EDX, suggests the presence of additional amorphous phases as often observed for SEI formed in organic electrolytes. ${ }^{4}$
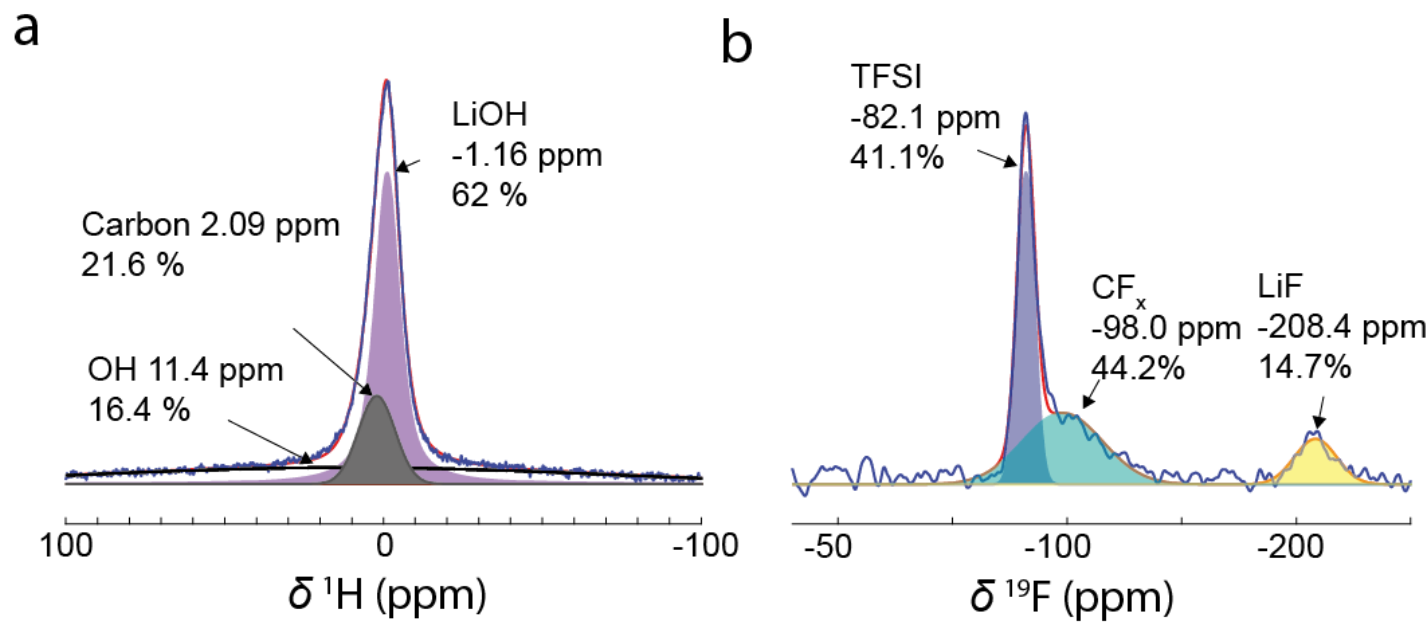

Figure 6. a) ${ }^{1} \mathrm{H}$ and b) ${ }^{19} \mathrm{~F}$ MAS NMR spectra of a gas diffusion layer hold at $-1.8 \mathrm{~V}$ vs. SHE in $20 \mathrm{~m}$ WiSE for $30 \mathrm{~min}$ (blue curve and red curve showing the raw and fitted data, respectively).

The chemical nature of the amorphous phases was thus analyzed by ex-situ solid-state NMR on a GDL electrode discharged at $-1.8 \mathrm{~V}$ for $30 \mathrm{~min}$. First, ${ }^{1} \mathrm{H}$ NMR spectrum (Figure 6a) confirmed the presence of $\mathrm{LiOH}$ as the main discharge product as indicated by the broad peak centered at around - $1 \mathrm{ppm}$ and confirmed by ${ }^{7} \mathrm{Li}$ NMR, while other environments could be assigned to residual water (Figure S7). The ${ }^{19} \mathrm{~F}$ spectrum (Figure $6 \mathrm{~b}$ ) reveals several peaks, with the most intense one around $-82 \mathrm{ppm}$ assigned to residual LiTFSI trapped in the SEI (Figure S7). Additionally, two other environments could be observed. The first one at around - 
207 ppm originates from $\mathrm{LiF}^{36,37}$ while the one at -98 ppm may correspond to $\mathrm{CF}_{\mathrm{x}}$ groups. Hence, the simultaneous presence of $\mathrm{CF}_{\mathrm{x}}$ groups together with $\mathrm{LiF}$ indicates fragmentation of $\mathrm{CF}_{3}$ groups during the formation of the amorphous part of the SEI. 


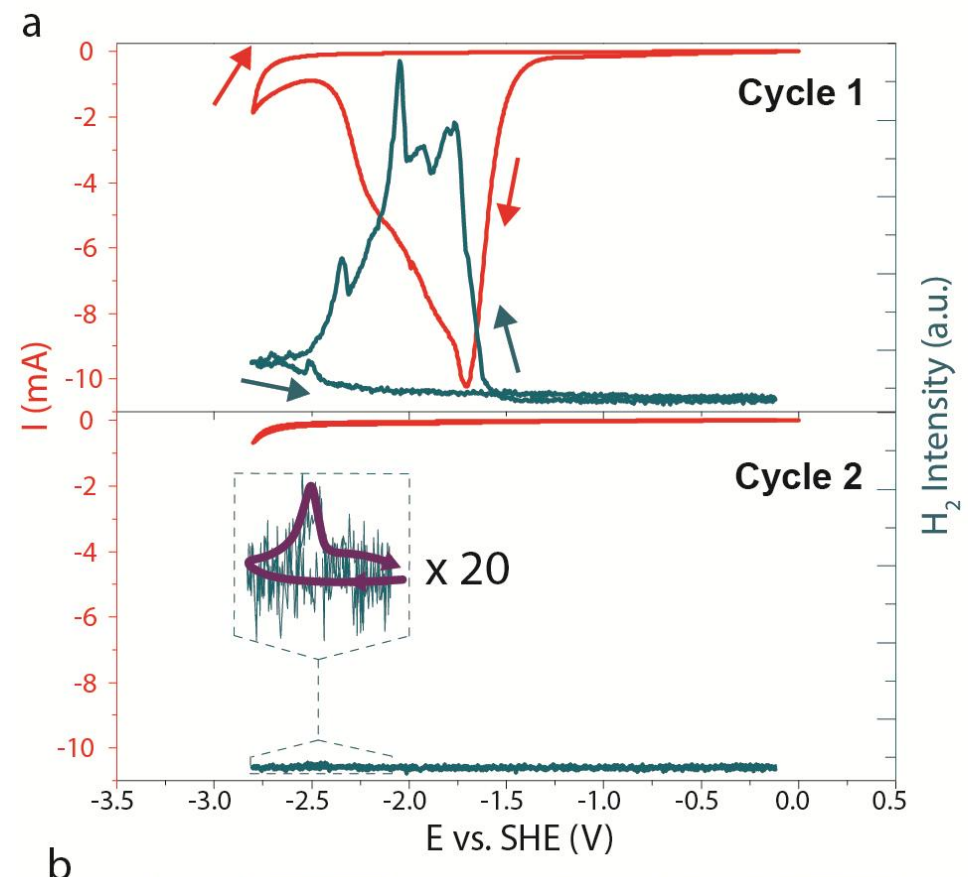

b

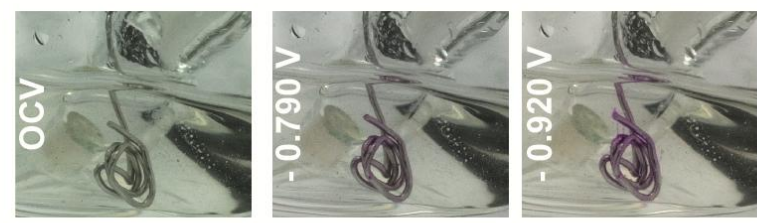

C

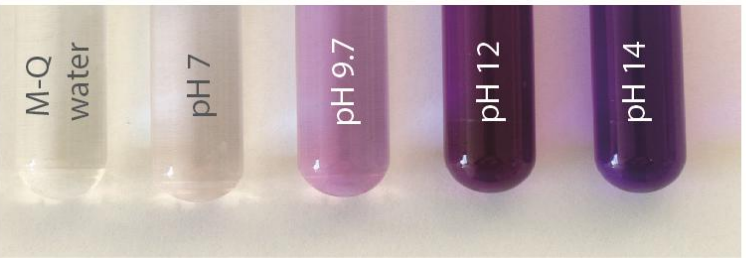

Figure 7. a) Cyclic voltammograms recorded on a glassy carbon plate electrode in $20 \mathrm{~m}$ LiTFSI electrolyte at $0.5 \mathrm{mV} . \mathrm{s}^{-1}$ under a continuous argon flow and OLEMS $\mathrm{H}_{2}$ generation monitoring for the first (top) and a second (bottom) cycle, arrows showing forward (reduction) and backward (going back to OCV) scans, purple plain line serves as a guide for the eyes b) pictures of a platinum wire cycled in reduction with a $5 \mathrm{mV} \cdot \mathrm{s}^{-1}$ sweep rate in $20 \mathrm{~m}$ LiTFSI electrolyte in presence of a $\mathrm{pH}$ indicator presenting a purple color in alkaline media as shown in the scale in c). 


\section{Mechanism interpretation: water reduction and instability of TFSI anions in strong}

alkaline media. As the only source of protons in the media comes from water molecules, they must be involved in the mechanism leading to the precipitation of $\mathrm{LiOH}$ for which two paths can be envisioned. First, it could be the result of an acid-base reaction between an organic base formed during TFSI reduction and water molecule $\left(\mathrm{R}^{-}+\mathrm{H}_{2} \mathrm{O}->\mathrm{B}-\mathrm{H}+\mathrm{OH}^{-}\right)$. Second, it could also originate from the reaction of $\mathrm{Li}^{+}$with $\mathrm{OH}^{-}$generated during the water reduction following the reaction $2 \mathrm{H}_{2} \mathrm{O}+2 \mathrm{e}^{-}>\mathrm{H}_{2}+2 \mathrm{OH}^{-}$. Hence, to discriminate between these two pathways, on-line electrochemical mass spectrometry (OLEMS) measurements were conducted in $20 \mathrm{~m}$ LiTFSI electrolyte to detect if gaseous $\mathrm{H}_{2}$ is evolved under reductive conditions. As shown in Figure 7, during the first cycle, an important generation of $\mathrm{H}_{2}$ is recorded during the cathodic peak previously described. Interestingly, in the following cycle, $\mathrm{H}_{2}$ evolution is nearly suppressed, which confirms the passivating role of the layer formed concomitantly with the HER in the first cycle. We could then demonstrate, following the change of color of o-Cresolphtahalein complexone used as a $\mathrm{pH}$ indicator that a strong basification occurs on the surface of the electrode upon HER owing to the generation of $\mathrm{OH}^{-}$ at the electrochemical interface following the reaction (1.a). Hence, with the presence of $\mathrm{Li}^{+}$ cations at the electrochemical interface (Figure 4), ${ }^{29}$ as well as the generation of $\mathrm{OH}^{-}$during the HER (Figure 7), and owing to the limited solubility of LiOH (approximatively $5 \mathrm{~m}$ ) compared to LiTFSI, the common ion effect can easily explain the precipitation of crystalline LiOH observed by XRD (Figure 5). Hence, the following mechanism is proposed:

$$
\begin{gathered}
\mathrm{H}_{2} \mathrm{O}+\mathrm{e}^{-}->1 / 2 \mathrm{H}_{2}+\mathrm{OH}_{(\text {solv })}^{-}(1 . \mathrm{a}) \\
\mathrm{OH}_{(\text {solv })}^{+}+\mathrm{Li}_{(\text {solv })}^{+}=\mathrm{LiOH}_{(\text {sol })}(1 . \mathrm{b})
\end{gathered}
$$




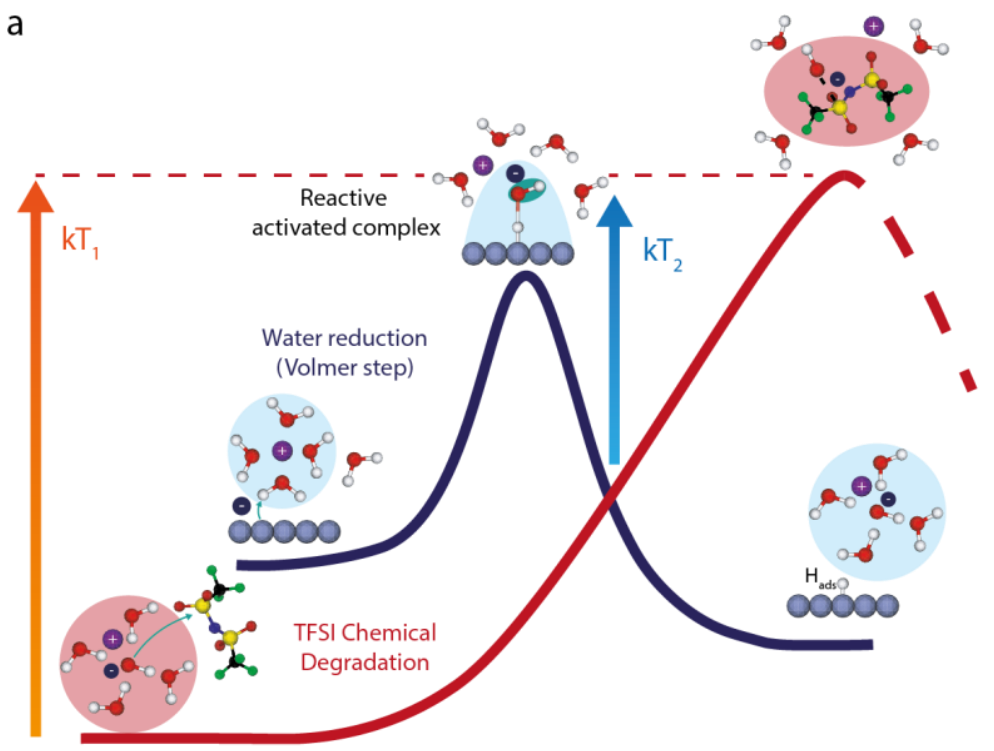

b

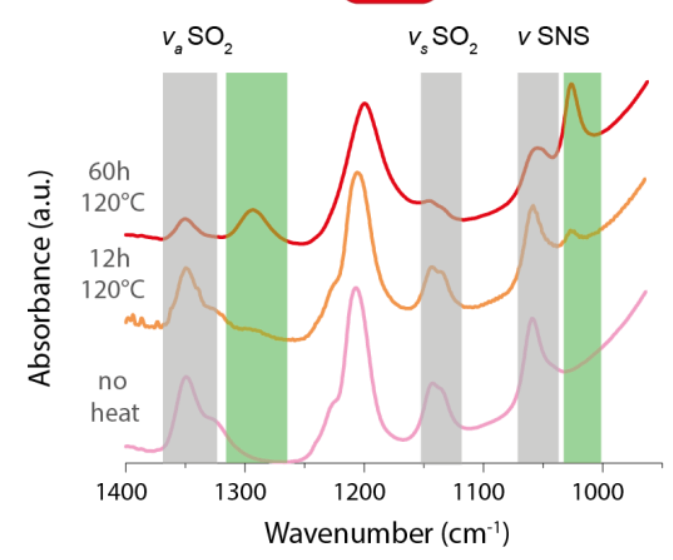

d

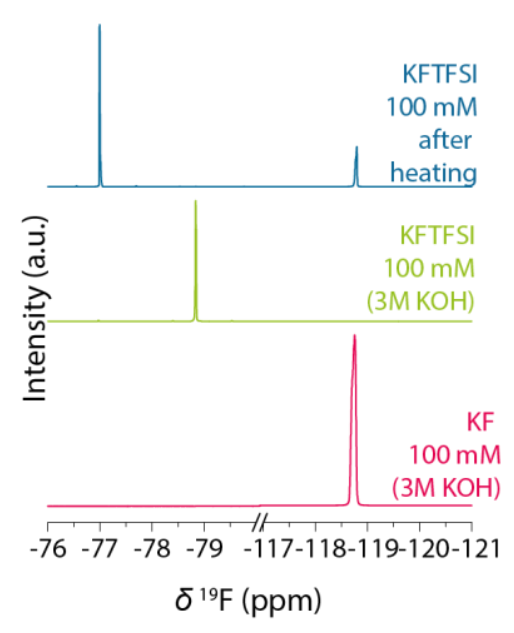

c

\section{$\mathrm{K}$}

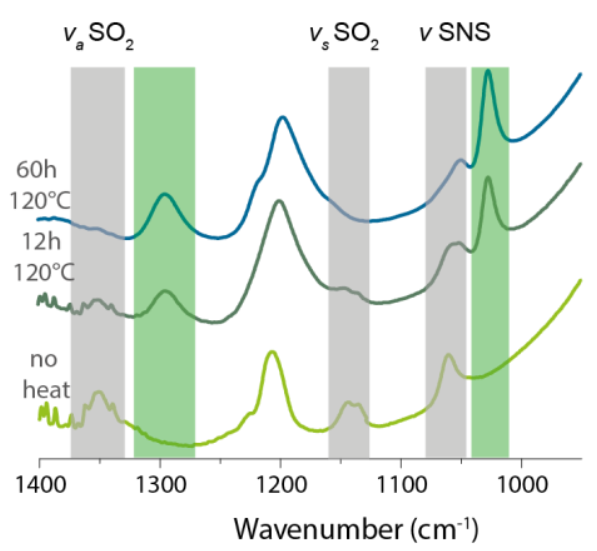

Figure 8. a) Schematic illustration for the greater reactivity of electrochemically generated hydroxiles species when compared to solvated bulk hydroxiles. FTIR analysis of the $100 \mathrm{mM}$ TFSI solution in 3M LiOH (b) and in $\mathrm{KOH}$ (c) before heating and after 12 and 60 hours at $120^{\circ} \mathrm{C}$ (spectra are not normalized). d) ${ }^{19} \mathrm{~F}$ NMR analysis of the $100 \mathrm{mM}$ KTFSI in $3 \mathrm{M} \mathrm{KOH}$ solution before (green) and after 60 hours at $120^{\circ} \mathrm{C}$ (blue) compared with the same analysis replacing KTFSI by KF (pink). 
However, none of these steps could explain the traces of fluorine and sulfur that were observed by solid-state NMR (Figure 6) and EDX analysis (Figure S3) and that were previously reported on the surface of $\mathrm{Li}^{+}$insertion materials. ${ }^{10,11,20}$ Even though TFSI anions were previously described as stable in a wide range of $\mathrm{pH}$, including strong alkaline media, ${ }^{38}$ electro-generated species are often more reactive than their chemical counterparts owing from the slow solvent reorganization when compared to the electron transfer, ${ }^{39,40}$ which can render TFSI anions unstable towards $\mathrm{OH}^{-}$species generated during the HER (Figure 8a). To mimic this increased reactivity, the stability of TFSI anions in alkaline environment was studied at high temperature. Thus, $3 \mathrm{M} \mathrm{LiOH}$ (resp. KOH) solutions containing $100 \mathrm{mM}$ of LiTFSI (resp. KTFSI) were introduced in hydrothermal bombs and heated for $12 \mathrm{~h}$ and $60 \mathrm{~h}$ at $120^{\circ} \mathrm{C}$. Resulting solutions were analyzed by FTIR and ${ }^{19} \mathrm{~F}$ liquid state NMR spectroscopy. FTIR results presented in Figure $8 \mathrm{~b}$ and $8 \mathrm{c}$ reveal that TFSI anions undergo a chemical degradation in these strong alkaline conditions. Indeed, after 60 hours of heating, the FTIR bands assigned to $\mathrm{SO}_{2}\left(1,350 \mathrm{~cm}^{-1}\right.$ and $\left.1,175 \mathrm{~cm}^{-1}\right)$ and $\operatorname{SNS}\left(1,160 \mathrm{~cm}^{-1}\right)$ bonds almost disappeared for both solutions, while new bands at around 1,290 and $1025 \mathrm{~cm}^{-1}$ appears. However, looking at the reaction mixture after only 12 hours in these conditions, different kinetics for the degradation of TFSI anions are observed for $\mathrm{Li}^{+}$and $\mathrm{K}^{+}$, with the degradation being faster with $\mathrm{K}^{+}$than with $\mathrm{Li}^{+}$. This result provides useful indications on the mechanistic pathway for TFSI degradation in alkaline conditions. Indeed, as $\mathrm{Li}^{+}$is a much stronger Lewis acid than $\mathrm{K}^{+}$, the nucleophilicity of hydroxile anions is greatly diminished in the presence of $\mathrm{Li}^{+}$cations. Hence, a nucleophilic attack of $\mathrm{OH}^{-}$on the sulfur atom of the TFSI, which were previously shown to possess a large Mulliken charge, ${ }^{43,44}$ can be proposed as a possible mechanism for TFSI alkaline hydrolysis. To confirm this hypothesis, proton decoupled ${ }^{19} \mathrm{~F}$ NMR spectra were recorded after TFSI hydrolysis (Figure 8d). As expected, the solution before hydrolysis shows only one peak at $-79.8 \mathrm{ppm}$, corresponding to the $\mathrm{CF}_{3}$ groups of TFSI anions. After heating for 
60 hours, two peaks at -77.0 and $-118.8 \mathrm{ppm}$ were observed in the ${ }^{19} \mathrm{~F}$ NMR spectrum. Comparing with a solution of $100 \mathrm{mM} \mathrm{KF}$ in $3 \mathrm{M} \mathrm{KOH}$, the peak at $-118.8 \mathrm{ppm}$ can be attributed to the presence of $\mathrm{F}^{-}$anions. This control experiment shows that under strong alkaline conditions such as the ones encountered during initial HER at the negative electrode in WiSEs, TFSI is unstable and some $\mathrm{LiF}$ is generated via the reaction of TFSI with hydroxiles. These results are in line with the previous ssNMR results and confirm the presence of two fluorine environments arising from the chemical fragmentation of the $\mathrm{CF}_{3}$ groups from TFSI under alkaline conditions. 


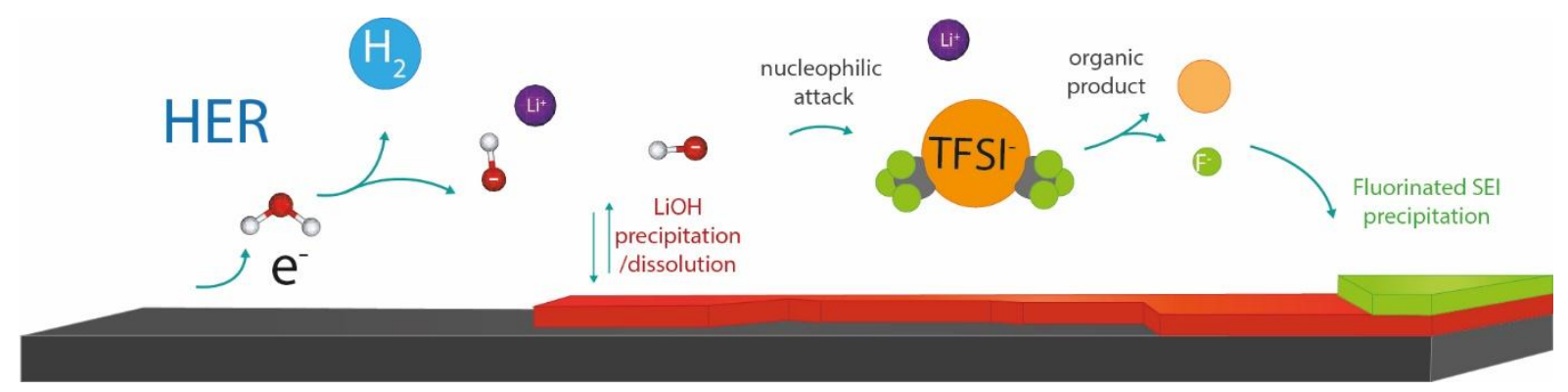

Figure 9. Schematic illustration of the formation of the SEI following a "water reduction mediated mechanism" occurring in 20 molar LiTFSI WiSE.

Gathering all these observations, we propose the following mechanism that contributes to the formation of the passivating layer at the negative electrode in WiSEs (Figure 9). First, as demonstrated by OLEMS, water is reduced at negative potential which leads to the formation of gaseous $\mathrm{H}_{2}$ and the release of $\mathrm{OH}^{-}$at the surface of the negative electrode. This process leads to the precipitation of $\mathrm{LiOH}$ on the surface of the electrode, as shown by the operando XRD experiment. Combining FTIR and ${ }^{19} \mathrm{~F}$ liquid NMR, we could then demonstrate that TFSI is decomposed in the presence of either the solid $\mathrm{LiOH}$ or $\mathrm{OH}^{-}$ions in solution which react with the electrophilic sulfur atom of TFSI anions through a nucleophilic attack. This attack generates $\mathrm{F}^{-}$anions as well as some organic compounds that precipitate with $\mathrm{Li}^{+}$ cations thanks to the common cation effect. Hence, a fluorinated SEI is eventually formed and allows cycling anode materials outside of the thermodynamic potential of the water.

Aside from this mechanism, we also explored the possibility of a direct electroreduction of TFSI anions at the negative electrode. For that, a TFSI-based ionic liquid was used owing to its similar electrochemical interface, when compared to WISEs, made of $\left[\mathrm{Li}_{\mathrm{x}} \mathrm{TFSI}_{\mathrm{y}}\right]$ aggregates (Figure 10). Using a dry $1 \mathrm{M}$ LiTFSI [Emim][TFSI] electrolyte, no significant cathodic current was measured by cyclic voltammetry at a potential at which a reduction peak could be observed in WISEs. Instead, when saturating the $1 \mathrm{M}$ LiTFSI 
[Emim][TFSI] electrolyte with water to reach a $\mathrm{Li}^{+} / \mathrm{H}_{2} \mathrm{O}$ ratio close to 2 (this ratio being $2.5 \mathrm{in}$ WISEs), an electrochemical behavior similar to the one measured in WISEs is observed, with a peak at $-1 \mathrm{~V}$ vs. SHE followed by another reduction event. These results reinforce that the products of water reduction catalyze the degradation of TFSI anions. 


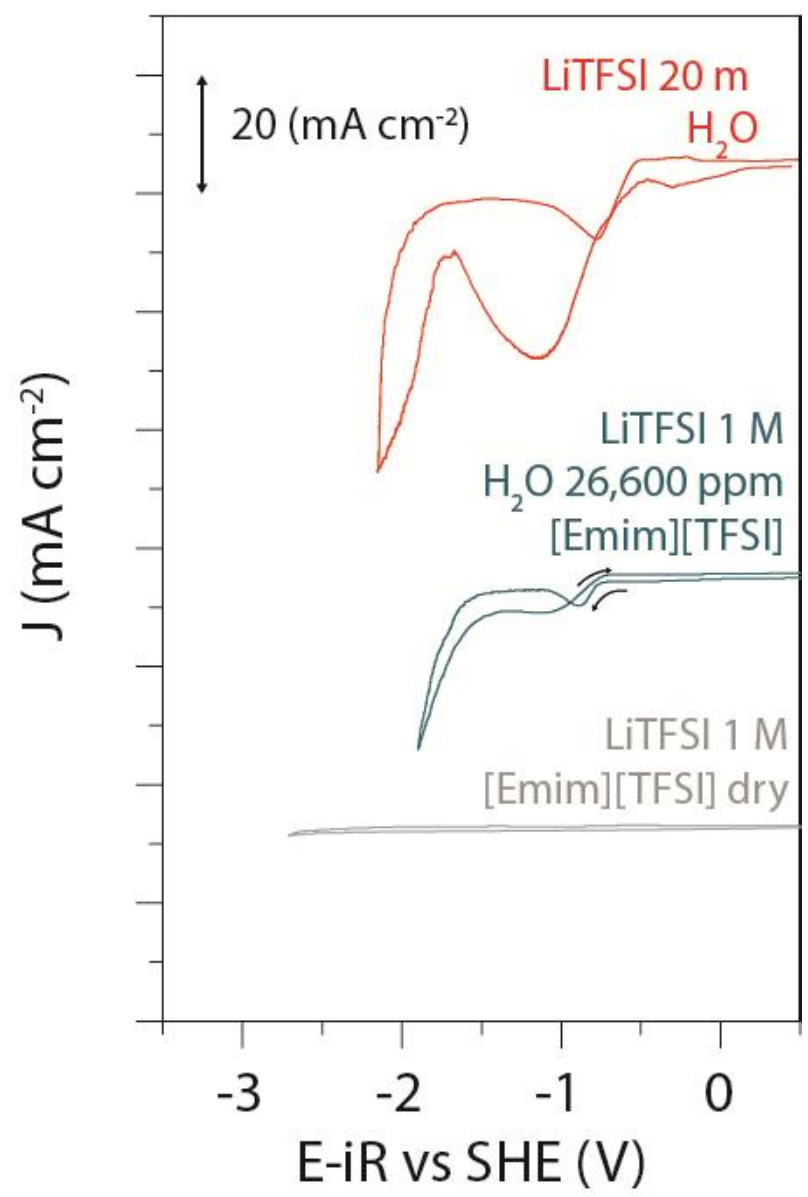

Figure 10. Cyclic voltammograms recorded at $100 \mathrm{mV} \cdot \mathrm{s}^{-1}$ on a platinum disk electrode rotated at a rotation speed of 1,600 rpm for the WISEs $20 \mathrm{~m}$ LiTFSI in $\mathrm{H}_{2} \mathrm{O}$ (red), 1 M LiTFSI in $\mathrm{H}_{2} \mathrm{O}$ saturated [Emim][TFSI] (blue) and $1 \mathrm{M}$ LiTFSI in dry [Emim][TFSI] (gray).

Having established that water reduction catalyzes the formation of the passivating layer, it is worth stressing out that unfortunately this SEI does not fully prevent further water reduction that occurs at lower potentials (- $2.5 \mathrm{~V}$ vs. SHE), as seen in the OLEMS measurements (Figure 7). This observation limits the choice of potential materials used as negative electrode in WiSEs. Indeed, they must match the two following conditions: a good 
mechanical resistance to minimize their exfoliation during the SEI formation cycles and perform $\mathrm{Li}^{+}$insertion at potentials higher than $-2.5 \mathrm{~V}$ vs. SHE $\left(0.5 \mathrm{~V}\right.$ vs. $\left.\mathrm{Li}^{+} / \mathrm{Li}\right)$. Hence, without further protection such as an hydrophobic coating, ${ }^{14}$ the use of negative electrode such as graphite will certainly be challenging in WISEs.

Nevertheless, this strategy may help to trigger the formation of more robust and efficient SEIs in organic Li batteries by adding low amounts of waters in organic TFSI-based electrolytes. Indeed, initial results demonstrate that the cycling behavior of metallic Lithium anode in $1 \mathrm{M}$ LiTFSI DME electrolyte can be improved by adding 1,000 ppm of water (Figure S8). Further experiments will be necessary to validate such approach, but the use of water as an additive in TFSI-based electrolyte could be seen as a promising strategy to explore.

\section{Conclusions}

In conclusion, we have demonstrated that under reductive conditions, water is initially reduced in TFSI-based WISEs, generating highly reactive $\mathrm{OH}^{-}$which can chemically react with TFSI anions following a nucleophilic attack. This reactivity leads to the degradation of the $\mathrm{CF}_{3}$ groups from TFSI and catalyzes the formation of a passivating layer composed of fluorinated products such as $\mathrm{LiF}$ and $\mathrm{CF}_{\mathrm{x}}$ that helps to prevent water reduction in aqueous electrolytes. Furthermore, the catalytic effect of water reduction on the degradation of TFSI was found not only to occur in WiSEs but in other systems, such as ILs.

While this understanding is rather fundamental, this approach could prove useful for the control of the SEI formation on the surface of negative electrodes and potentially the development of metallic $\mathrm{Li}$ anode in organic systems $\left(\mathrm{Li}(\mathrm{M}), \mathrm{Li}_{-} \mathrm{O}_{2}, \mathrm{Li}-\mathrm{S}, \ldots\right)$. Finally, as for 
new discoveries, further works will be needed to master this chemical SEI formation but strategies such as the introduction of anions donor salt and/or additives could prove promising.

\section{Conflicts of Interest}

The authors declare no conflict of interest.

\section{Acknowledgments}

N.D. would like to thanks financial support from Ecole normale supérieure (Paris). Access to SEM-FEG \& EDX instrumentation was given by the Instut des Matériaux de Paris Centre (IMPC FR2482) and was funded by UPMC, CNRS and by the C'Nano projects of the Région Ile-de-France. Chunzhen Yang is acknowledged for his help with the operando XRD measurement. Victor Mougel is acknowledged for insightful discussion about liquid-state NMR experimental protocols and for providing the access to the liquid-state NMR spectrometer. Jean-Marie Tarascon is acknowledged for fruitful discussions and comments on the manuscript.

\section{Authors contribution}

N.D. and A.G designed the experiments. N.D. conducted the electrochemical measurements, as well as liquid NMR, FTIR, DEMS and XRD measurements. P.L. performed the EQCM measurements. B.M. performed the SEM-EDX analysis. E.S. and M.D. performed the ssNMR as well as the NMR analysis. N.D. and A.G. wrote the manuscript that all authors revised. 


\section{REFERENCES}

1 M. Armand and J.-M. Tarascon, nature, 2008, 451, 652.

2 P. Verma, P. Maire and P. Novák, Electrochimica Acta, 2010, 55, 6332-6341.

3 K. Xu, Chem. Rev., 2014, 114, 11503-11618.

4 A. Wang, S. Kadam, H. Li, S. Shi and Y. Qi, Npj Comput. Mater., 2018, 4, 15.

5 W. Li, W. R. McKinnon and J. R. Dahn, J. Electrochem. Soc., 1994, 141, 2310-2316.

6 W. Li, J. R. Dahn and D. S. Wainwright, Science, 1994, 264, 1115-1118.

7 D. Larcher and J.-M. Tarascon, Nat. Chem., 2015, 7, 19-29.

8 Y. Yamada, K. Furukawa, K. Sodeyama, K. Kikuchi, M. Yaegashi, Y. Tateyama and A. Yamada, J. Am. Chem. Soc., 2014, 136, 5039-5046.

9 J. Wang, Y. Yamada, K. Sodeyama, C. H. Chiang, Y. Tateyama and A. Yamada, Nat. Commun., 2016, 7, 12032.

10L. Suo, O. Borodin, T. Gao, M. Olguin, J. Ho, X. Fan, C. Luo, C. Wang and K. Xu, Science, 2015, 350, 938-943.

11 Y. Yamada, K. Usui, K. Sodeyama, S. Ko, Y. Tateyama and A. Yamada, Nat. Energy, 2016, 1, 16129.

12L. Suo, O. Borodin, W. Sun, X. Fan, C. Yang, F. Wang, T. Gao, Z. Ma, M. Schroeder, A. von Cresce, S. M. Russell, M. Armand, A. Angell, K. Xu and C. Wang, Angew. Chem. Int. Ed., 2016, 55, 7136-7141.

13F. Wang, L. Suo, Y. Liang, C. Yang, F. Han, T. Gao, W. Sun and C. Wang, Adv. Energy Mater., 2017, 7, 1600922.

14C. Yang, J. Chen, T. Qing, X. Fan, W. Sun, A. von Cresce, M. S. Ding, O. Borodin, J. Vatamanu, M. A. Schroeder, N. Eidson, C. Wang and K. Xu, Joule, 2017, 1, 122-132.

15C. Yang, X. Ji, X. Fan, T. Gao, L. Suo, F. Wang, W. Sun, J. Chen, L. Chen, F. Han, L. Miao, K. Xu, K. Gerasopoulos and C. Wang, Adv. Mater., 2017, 29, 1701972.

16L. Suo, O. Borodin, Y. Wang, X. Rong, W. Sun, X. Fan, S. Xu, M. A. Schroeder, A. V. Cresce, F. Wang, C. Yang, Y.-S. Hu, K. Xu and C. Wang, Adv. Energy Mater., , DOI:10.1002/aenm.201701189.

17D. P. Leonard, Z. Wei, G. Chen, F. Du and X. Ji, ACS Energy Lett., 2018, 3, 373-374.

18Q. Dong, X. Yao, Y. Zhao, M. Qi, X. Zhang, H. Sun, Y. He and D. Wang, Chem, , DOI:10.1016/j.chempr.2018.02.015.

19P. Lannelongue, R. Bouchal, E. Mourad, C. Bodin, M. Olarte, S. le Vot, F. Favier and O. Fontaine, J. Electrochem. Soc., 2018, 165, A657-A663.

20L. Suo, D. Oh, Y. Lin, Z. Zhuo, O. Borodin, T. Gao, F. Wang, A. Kushima, Z. Wang, H.-

C. Kim, Y. Qi, W. Yang, F. Pan, J. Li, K. Xu and C. Wang, J. Am. Chem. Soc., 2017, 139, 18670-18680.

21 D. Strmcnik, M. Uchimura, C. Wang, R. Subbaraman, N. Danilovic, D. van der Vliet, A. P. Paulikas, V. R. Stamenkovic and N. M. Markovic, Nat. Chem., 2013, 5, 300-306.

22 N. Dubouis, C. Yang, R. Beer, L. Ries, D. Voiry and A. Grimaud, ACS Catal., 2018, 8, 828-836.

23 O. Borodin, L. Suo, M. Gobet, X. Ren, F. Wang, A. Faraone, J. Peng, M. Olguin, M.

Schroeder, M. S. Ding, E. Gobrogge, A. von Wald Cresce, S. Munoz, J. A. Dura, S.

Greenbaum, C. Wang and K. Xu, ACS Nano, 2017, 11, 10462-10471.

24L. Coustan, G. Shul and D. Bélanger, Electrochem. Commun., 2017, 77, 89-92.

25L. Coustan, K. Zaghib and D. Bélanger, J. Power Sources, 2018, 399, 299-303.

26 J. C. Hindman, J. Chem. Phys., 1962, 36, 1000-1016.

27 C. H. Giammanco, P. L. Kramer and M. D. Fayer, J. Phys. Chem. B, 2016, 120, 999710009. 
28T. Mandai, K. Yoshida, K. Ueno, K. Dokko and M. Watanabe, Phys. Chem. Chem. Phys., $2014,16,8761$.

29J. Vatamanu and O. Borodin, Ramifications of Water-in-Salt Interfacial Structure at Charged Electrodes for Electrolyte Electrochemical Stability, 2017, vol. 8.

30Z. Li, G. Jeanmairet, T. Mendez-Morales, B. Rotenberg and M. Salanne, figshare, , DOI:10.26434/chemrxiv.6933110.v1.

31 W. D. Sides and Q. Huang, Electrochimica Acta, 2018, 266, 185-192.

32 V. Tsionsky, L. Daikhin and E. Gileadi, J. Electrochem. Soc., 1996, 143, 2240-2245.

33 M. D. Levi, G. Salitra, N. Levy, D. Aurbach and J. Maier, Nat. Mater., 2009, 8, 872-875.

34 W.-Y. Tsai, P.-L. Taberna and P. Simon, J. Am. Chem. Soc., 2014, 136, 8722-8728.

35 J. M. Griffin, A. C. Forse, W.-Y. Tsai, P.-L. Taberna, P. Simon and C. P. Grey, Nat. Mater., 2015, 14, 812-819.

36B. M. Meyer, N. Leifer, S. Sakamoto, S. G. Greenbaum and C. P. Grey, Electrochem. Solid-State Lett., 2005, 8, A145.

37D. S. Hall, U. Werner-Zwanziger and J. R. Dahn, J. Electrochem. Soc., 2017, 164, A2171A2175.

38 S. F. Lux, L. Terborg, O. Hachmöller, T. Placke, H.-W. Meyer, S. Passerini, M. Winter and

S. Nowak, J. Electrochem. Soc., 2013, 160, A1694-A1700.

39C. Hartnig and M. T. M. Koper, J. Am. Chem. Soc., 2003, 125, 9840-9845.

40E. Santos, M. T. M. Koper and W. Schmickler, Chem. Phys., 2008, 344, 195-201.

41 P. C. Howlett, E. I. Izgorodina, M. Forsyth and D. R. MacFarlane, Z. Für Phys. Chem., 2006, 220, 1483-1498.

42 C. Yang, O. Fontaine, J.-M. Tarascon and A. Grimaud, Angew. Chem. Int. Ed., 2017, 56, 8652-8656.

43D. Benrabah, R. Arnaud and J. Y. Sanchez, Electrochimica Acta, 1995, 40, 2437-2443.

44I. Rey, P. Johansson, J. Lindgren, J. C. Lassègues, J. Grondin and L. Servant, J. Phys. Chem. A, 1998, 102, 3249-3258. 
TOC

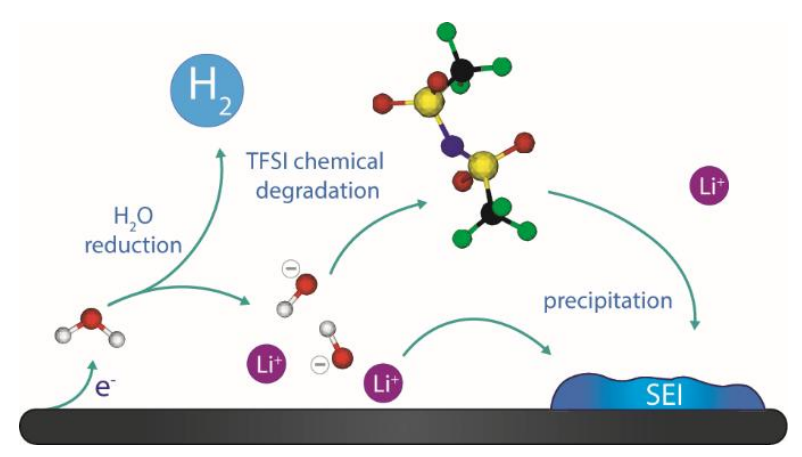

